\title{
Activation of peroxisome proliferator activated receptor alpha ameliorates ethanol mediated liver fibrosis in mice
}

\author{
Yue-Min Nan ${ }^{1 *}$, Ling-Bo Kong ${ }^{1}$, Wei-Guang Ren ${ }^{1}$, Rong-Qi Wang ${ }^{1}$, Jing-Hua Du', Wen-Cong Li', Su-Xian Zhao', \\ Yu-Guo Zhang', Wen-Juan Wu', Hai-Ling Di', Ya Li' and Jun Yu
}

\begin{abstract}
Background: Peroxisome proliferator activated receptor alpha (PPARa) ameliorates ethanol induced hepatic steatohepatitis. However, its role in alcoholic liver fibrosis has not been fully clarified. The aim of this study was to elucidate the effect and the molecular basis of PPARa in ethanol induced liver fibrosis in mice.

Methods: C57BL/6J mice were fed with 4\% ethanol-containing Lieber-DeCarli liquid diet for eight weeks, and intraperitoneal injected with $5 \%$ carbon tetrachloride $\left(\mathrm{CCl}_{4}\right)$ for the last four weeks to induce alcoholic liver fibrosis. PPARa agonist WY14643 was administered to mice during the last couple of weeks. The effects of PPARa induction on liver histology, activation of hepatic stellate cells (HSCs), as well as hepatic expression of inflammatory and fibrogenic factors were assessed.

Results: The ethanol plus $\mathrm{CCl}_{4}$ treated mice exhibited progressive liver injury including piecemeal necrosis of hepatocytes, severe inflammatory cells infiltration and bridging fibrosis. This was accompanied by down-regulated hepatic expression of PPARa and the protective cytokines adiponectin, heme oxygenase-1 and interleukin-10. Additionally, up-regulation of the proinflammatory cytokine tumor necrosis factor-alpha, as well as the profibrogenic genes osteopontin, transforming growth factor-beta 1, visfatin, phosphatidylinositol 3-kinase, matrix metalloproteinase-2 (MMP-2) and MMP-9 was observed. WY14643 treatment restored expression of cytokines altered by ethanol plus $\mathrm{CCl}_{4}$ treatment and concomitantly ameliorated the liver injury.
\end{abstract}

Conclusions: The present study provides evidence for the protective role of PPARa induction in ameliorating ethanol mediated fibrosis through mediation of inflammatory and fibrogenic factors.

Keywords: Peroxisome proliferator activated receptor alpha, Liver, Ethanol, Fibrosis, Animal experiment

\section{Background}

Alcoholic liver fibrosis is a severe form of alcoholic liver disease (ALD), which may progress to liver cirrhosis and hepatocellular carcinoma. Hepatic ethanol metabolism leads to the release of reactive oxygen species (ROS) and generation of lipid peroxidation products [1], which directly damage hepatocyte membranes and organelles, leading to inflammatory responses [2], including activation of Kupffer cells and subsequent release of proinflammatory and profibrogenic cytokines, such as tumor necrosis factor alpha

\footnotetext{
* Correspondence: nanyuemin@163.com

${ }^{1}$ Department of Traditional and Western Medical Hepatology, Third Hospital of Hebei Medical University, Shijiazhuang, China

Full list of author information is available at the end of the article
}

(TNF- $\alpha$ ) and transforming growth factor beta 1 (TGF- $\beta 1$ ) [3]. TGF- $\beta 1$ plays a crucial role in the development of hepatic fibrosis [4], through transdifferentiating quiescent hepatic stellate cells (HSCs) into myofibroblast-like cells, suppressing degradation and stimulating production of extracellular matrix (ECM). It is of great practical significance to identify potent pharmacological agents which target the activated HSCs and fibrogenic mediators to protect against ethanol-related liver fibrosis.

Previously, we demonstrated the role of nuclear transcription factor peroxisome proliferators activated receptor alpha (PPAR $\alpha)$ in lipid homeostasis and modulation of inflammatory responses in alcoholic steatohepatitis [5]. Induction of PPAR $\alpha$ significantly ameliorated the severity of

\section{Biomed Central}


ethanol induced liver injury by regulating expression of lipid metabolism and inflammation related genes. However, the role of PPAR $\alpha$ in alcoholic liver fibrosis, the more severe form of ALD, remains largely unknown. In the present study, the underlying molecular mechanisms of ethanol induced hepatic fibrosis and the effect of PPAR $\alpha$ in the pathogenesis of alcohol-induced liver fibrosis were elucidated.

\section{Results}

Activation of PPARa by WY14643 lowered the serum alanine aminotransferase (ALT) and aspartic transaminase (AST) levels in mice under ethanol plus carbon tetrachloride $\left(\mathrm{CCl}_{4}\right)$ treatment

As shown in Figure 1, mice treated with ethanol or ethanol plus $\mathrm{CCl}_{4}$ showed significantly higher serum ALT and AST levels compared with the control mice, $(P<0.01)$, especially in ethanol plus $\mathrm{CCl}_{4}$ group, which showed more pronounced liver injury. However, a significant reduction of serum ALT and AST levels $(P<0.01)$ was noticed after WY14643 treatment.

\section{Reversal of liver injury induced by ethanol and $\mathrm{CCl}_{4}$ after activation of PPARa}

Moderate macrosteatosis and mild inflammatory infiltration were exhibited in the liver sections of mice fed with ethanol liquid diet. Notably, pronounced inflammatory infiltration, piecemeal hepatocyte necrosis, perisinusoidal and bridging fibrosis were found in the liver sections of mice administrated with ethanol plus $\mathrm{CCl}_{4}$. Treatment with PPAR $\alpha$ agonist WY14643 significantly ameliorated the liver injury (Figure 2A, 2B and 2D).

\section{Effect of PPARa induction on activation of HSCs in} ethanol and $\mathrm{CCl}_{4}$ induced liver fibrosis in mice

We evaluated the role of PPAR $\alpha$ in the development of liver fibrosis by assessing the hepatic expression of $\alpha$-smooth muscle actin ( $\alpha$-SMA), a well-known marker of activated HSCs. Compared with control or ethanol treated mice, markedly increased $\alpha$-SMA expression in the activated HSCs and fibrotic areas of liver sections was observed in ethanol plus $\mathrm{CCl}_{4}$ treated mice, which was significantly blunted by WY14643 treatment (Figure 2C).

Hepatic PPARa expression in mice fed with ethanol liquid diet and/or intraperitoneally injected with $\mathrm{CCl}_{4}$, and treated with WY14643

Hepatic PPAR $\alpha$ mRNA and protein expressions were down-regulated by ethanol treatment, and further decreased by ethanol plus $\mathrm{CCl}_{4}$ administration. WY14643 administration restored the expression level of PPAR $\alpha$ in ethanol plus $\mathrm{CCl}_{4}$ treated mice (Figure 3).

\section{Induction of PPARa regulated hepatic expression of inflammatory cytokines}

To explore the mechanisms of PPAR $\alpha$ activation in alleviating ethanol related liver injury, we assessed hepatic mRNA expression levels of inflammatory cytokines. Ethanol treatment increased hepatic expression of the proinflammatory factor tumor necrosis factor-alpha (TNF- $\alpha$ ), and reduced expression of the anti-inflammatory factor interleukin-10 (IL-10). Co-administration of ethanol and $\mathrm{CCl}_{4}$ showed an obviously additive effect in altering TNF- $\alpha$ and IL-10 expression. This action was significantly blunted by WY14643 treatment $(P<0.01)$ (Figure 4$)$.

\section{Activation of PPARa suppressed hepatic expression of profibrogenic cytokines}

To seek an explanation for the ameliorated liver fibrosis under WY14643 administration, hepatic expression levels of profibrogenic genes were investigated. As shown in Figure 5, ethanol treatment increased hepatic osteopontin $(\mathrm{OPN})$, transforming growth factor-beta 1 (TGF- $\beta 1$ ), visfatin, phosphatidylinositol 3-kinase (PI3K), matrix metalloproteinase-2 (MMP-2), MMP-9 mRNA and protein expression $(P<0.05)$. A further up-regulation of these genes was noted in mice treated with ethanol plus $\mathrm{CCl}_{4}(P<0.05)$. WY14643 suppressed OPN, TGF- $\beta 1$, visfatin, PI3K, MMP-2 and MMP-9 mRNA and
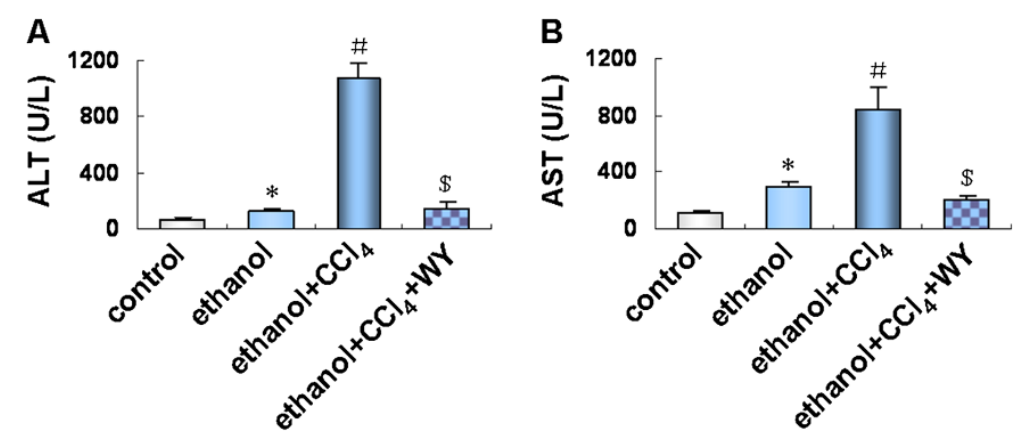

Figure 1 Effects of WY14643 on serum alanine aminotransferase (ALT) and aspartic transaminase (AST) levels. (A) Serum ALT levels. (B) Serum AST levels. ${ }^{*} P<0.01$, vs. control group; ${ }^{\#} P<0.01$, vs. ethanol group; ${ }^{\$} P<0.01$, vs. ethanol $+\mathrm{CCl}_{4}$ group. $C C \mathrm{l}_{4}$, carbon tetrachloride; WY, WY14643. 


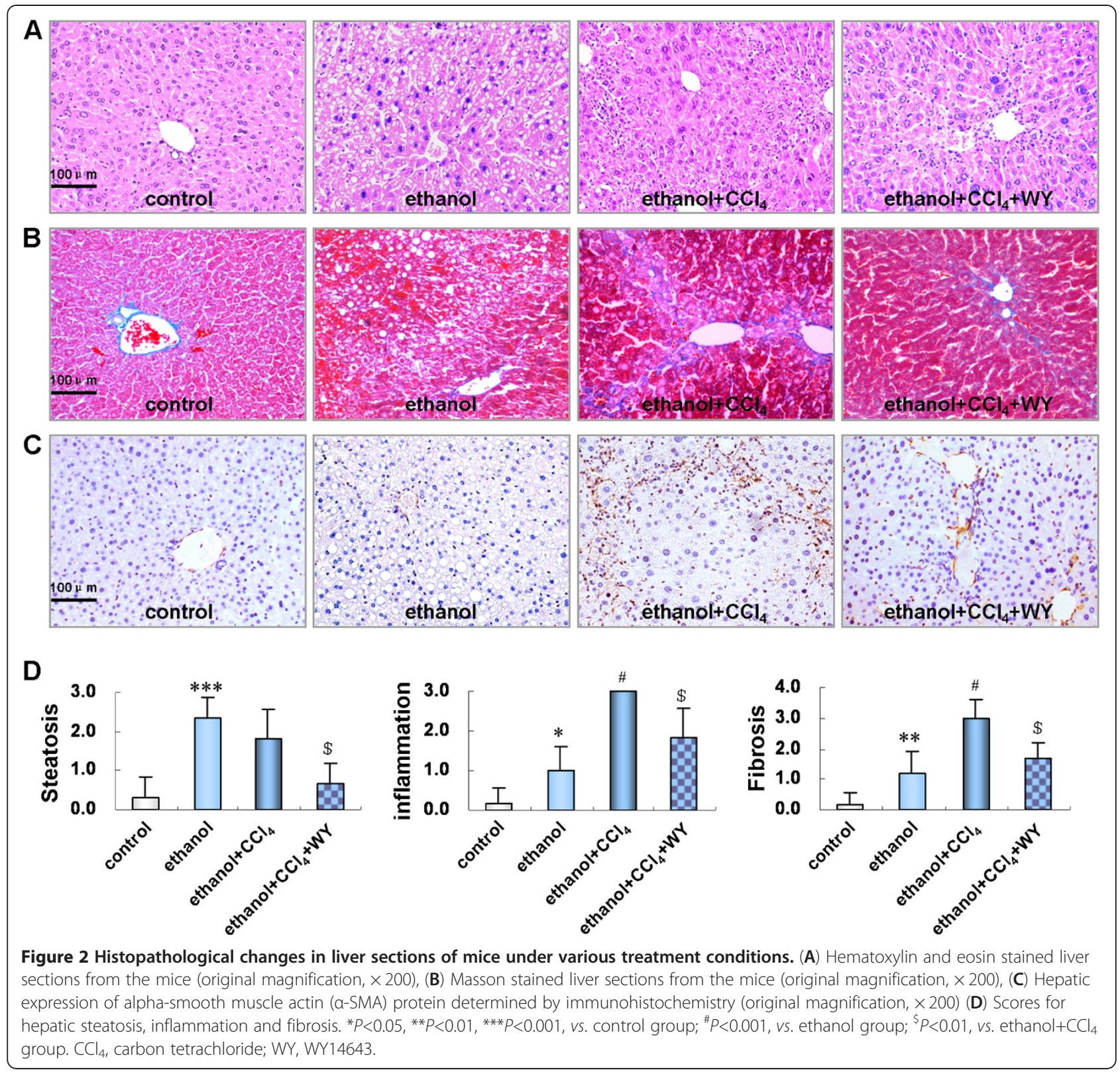

protein expression in ethanol plus $\mathrm{CCl}_{4}$ treated mice $(P<0.01)$.

\section{Activation of PPARa enhanced hepatic expression of anti- fibrotic cytokines}

Hepatic expression of anti-fibrotic genes was also assessed to clarify the underlying mechanism of the protective role of PPAR $\alpha$. Ethanol treatment reduced adiponectin mRNA and protein expression $(P<0.01)$, but increased heme oxygenase-1 $(\mathrm{HO}-1)$ expression $(P<0.05)$. Ethanol plus $\mathrm{CCl}_{4}$ treatment further decreased adiponectin and increased HO-1 expression $(P<0.05)$. WY14643 prominently up-regulated adiponectin and HO-1 $(P<0.01$ and $P<0.001)$ mRNA and protein expression in ethanol plus $\mathrm{CCl}_{4}$ treated mice (Figure 6).

\section{Discussion}

Alcoholic liver fibrosis is characterized by severe liver inflammatory response and fibrosis owing to augmented oxidative stress as well as generation of cell-toxic and profibrogenic ethanol metabolites, such as acetaldehyde and lipid oxidation products, which cause hepatocellular injury and activation of HSCs. A representative animal model of alcoholic liver fibrosis should reflect the characteristic metabolic changes and typical histological lesions of progressive fibrosing steatohepatitis, enabling ascertainment of pathogenesis and evaluation of drug therapy. In the 

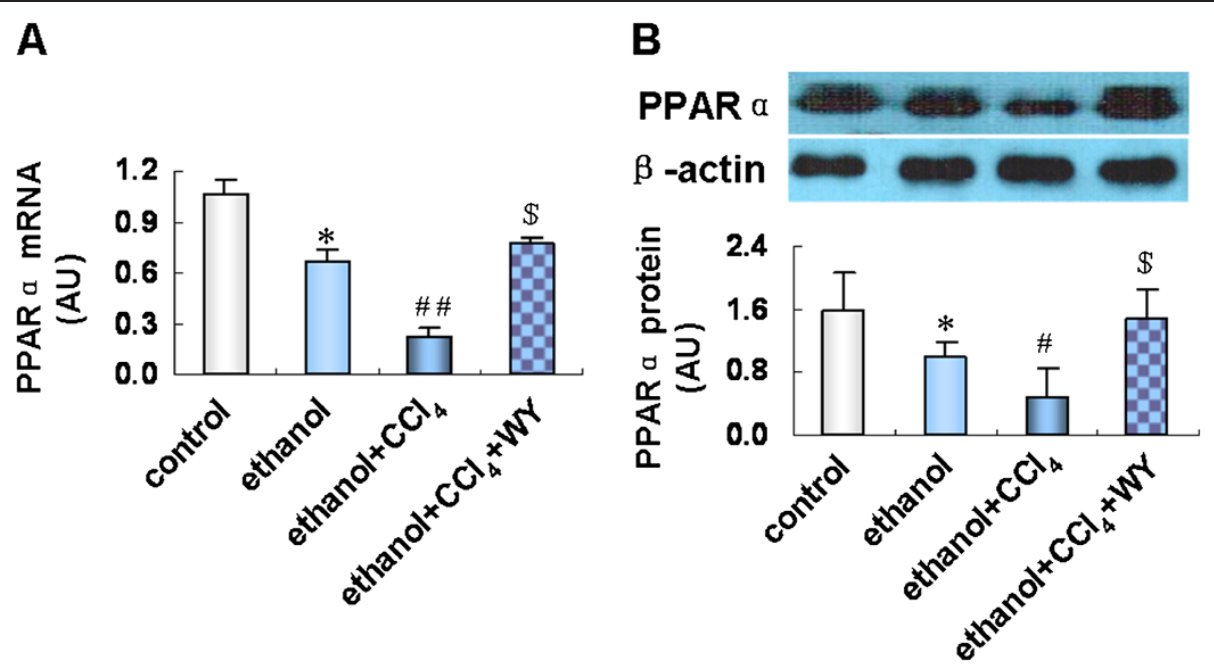

Figure 3 Effect of WY14643 on hepatic expression of peroxisome proliferators activated receptor alpha (PPARa). (A) Expression level of PPARa mRNA and (B) protein in various treatment groups. ${ }^{*} P<0.01$, vs. control group; ${ }^{\#} P<0.05,{ }^{\# \#} P<0.001$, vs. ethanol group; ${ }^{\$} P<0.001$, vs. ethanol $+C C l_{4}$ group. $\mathrm{CCl}_{4}$, carbon tetrachloride; WY, WY14643.

present study, we established an experimental model of alcoholic liver fibrosis by feeding C57BL/6J mice with $4 \%$ ethanol-containing Lieber-DeCarli liquid diet for 8 weeks and combined with $5 \% \mathrm{CCl}_{4}$ intraperitoneal injection for the last 4 weeks. After the combined administration, the mice rapidly and consistently developed alcoholic liver fibrosis manifested histologically by pronounced inflammatory infiltration, piecemeal hepatocellular necrosis, perisinusoidal and bridging fibrosis, together with enhanced hepatic expression of $\alpha$-SMA, as well as significantly elevated serum ALT and AST levels. Conversely, ethanol treatment caused moderate macrosteatosis and mild inflammatory infiltration in the mice liver. These findings indicated that an alcoholic liver fibrosis model could be established rapidly and successfully by feeding mice ethanol liquid diet combined with a small amount of $\mathrm{CCl}_{4}$. intraperitoneal injection. Ethanol was the key mediator to induce liver injury, whilst $\mathrm{CCl}_{4}$ accelerated the progression of liver injury by increasing lipid accumulation [6,7] and enhancing oxidative stress $[8,9]$.

With the progression of liver fibrosis, hepatic PPAR $\alpha$ expression was reduced, suggesting that abnormal expression and/or dysfunction of PPAR $\alpha$ might be involved in the development of ethanol plus $\mathrm{CCl}_{4}$ induced liver injury. We further demonstrated that induction of PPAR $\alpha$ by specific agonist WY14643 administration for two weeks prominently attenuated liver injury, as evidenced by decreased serum ALT and AST levels, diminished inflammatory response, reduced collagen deposition, as well as suppressed activation of HSCs. These results indicated that PPAR $\alpha$ played an important protective role in the progression of alcoholic liver fibrosis.

Oxidative stress and release of inflammatory cytokines induced by ethanol metabolism can evoke the activation of HSCs. Once activated, HSCs migrate to the site of liver injury and secrete excessive ECM [10], which is the pivotal
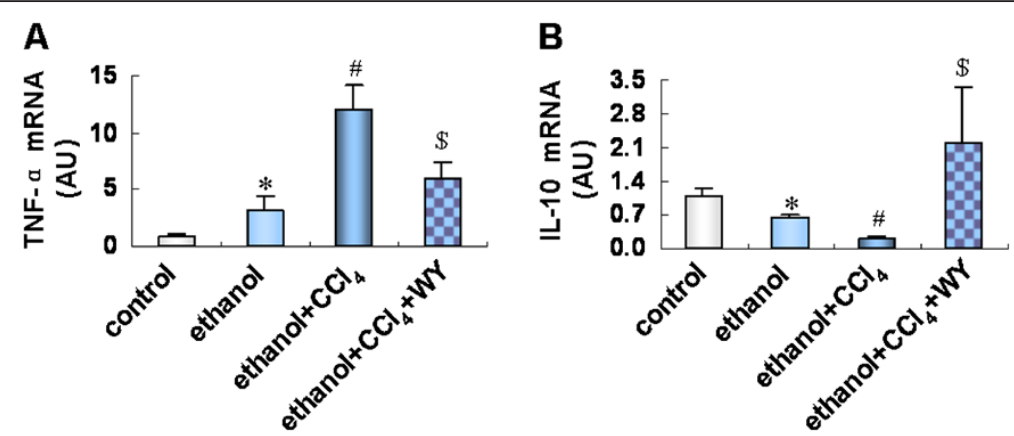

Figure 4 Effect of peroxisome proliferators activated receptor alpha (PPARa) induction on hepatic expression of inflammatory factors. (A) Expression level of tumor necrosis factor-alpha (TNF-a) and (B) interleukin-10 (IL-10) mRNA in various treatment groups. ${ }^{*} P<0.01$, vs. control group; ${ }^{\#} P<0.01$, vs. ethanol group; ${ }^{\$} P<0.01$, vs. ethanol $+C C l_{4}$ group. $C C_{4}$, carbon tetrachloride; $W Y$, WY14643. 

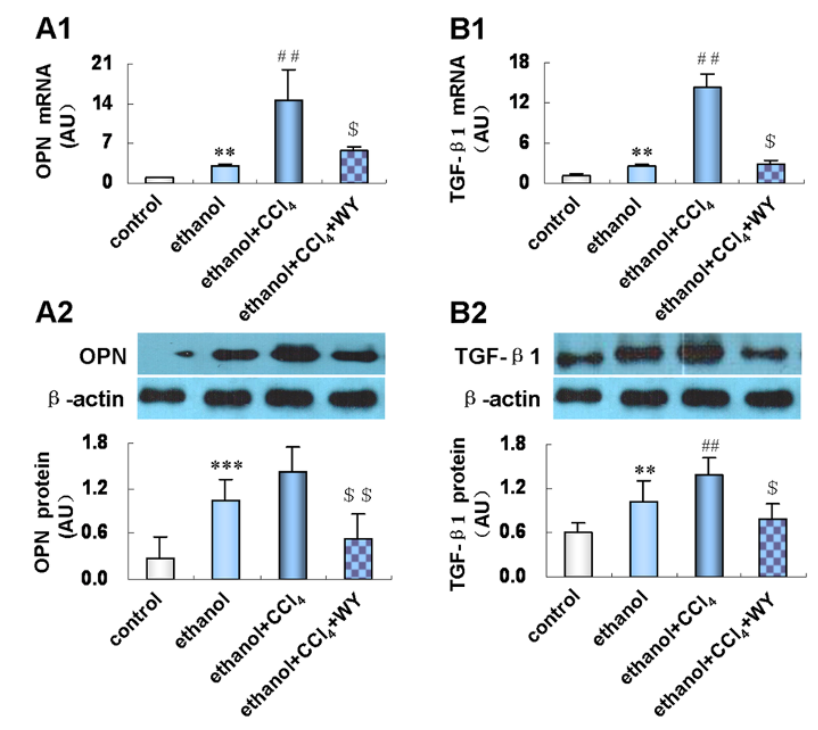

B2
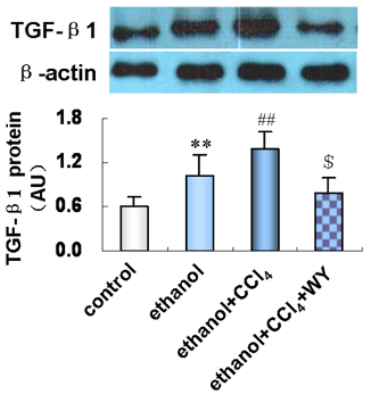

D1
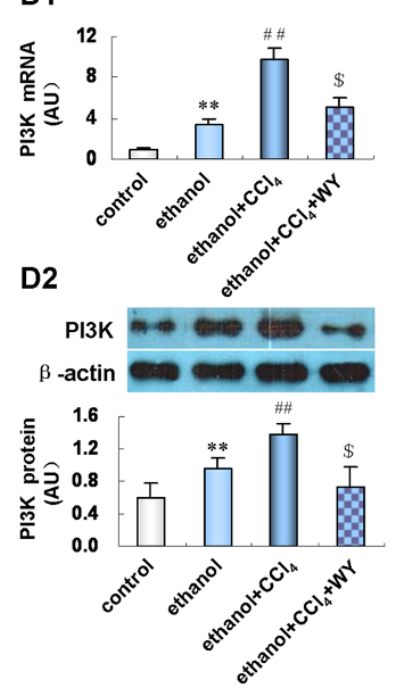

E1

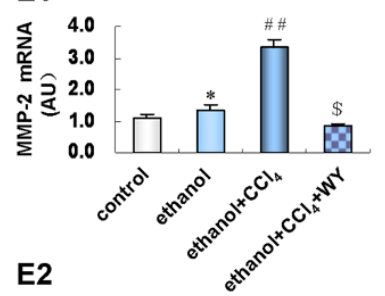

MMP-2

$\beta$-actin

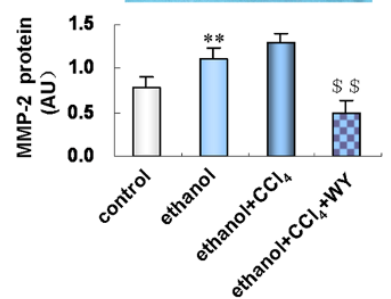

C1
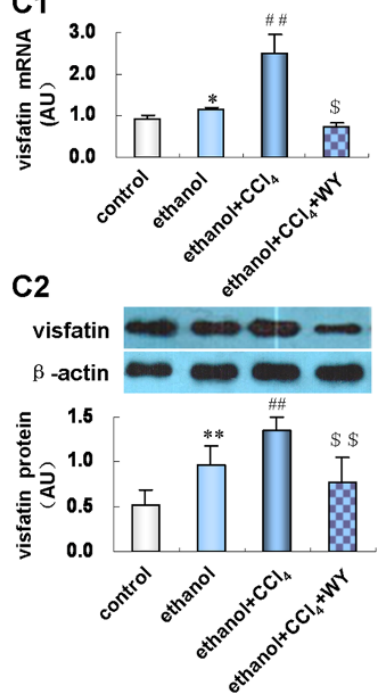

F1
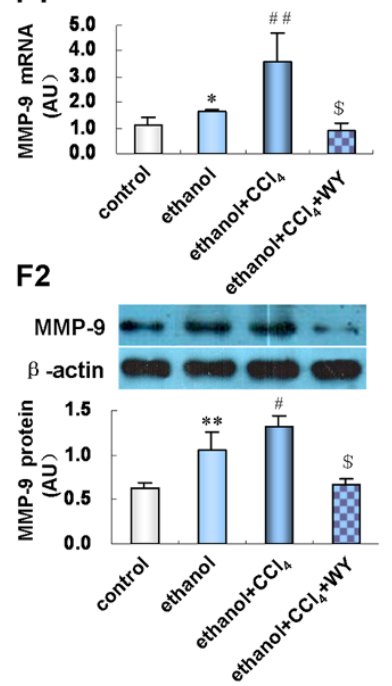

Figure 5 Effect of peroxisome proliferators activated receptor alpha (PPARa) induction on hepatic expression of profibrotic factors. (A1) Expression level of osteopontin (OPN) mRNA and (A2) protein; (B1) Expression level of transforming growth factor-beta 1 (TGF- $\beta 1$ ) mRNA and (B2) protein; (C1) Expression level of visfatin mRNA and (C2) protein; (D1) Expression level of phosphatidylinositol 3-kinase (PI3K) mRNA and (D2) protein; (E1) Expression level of matrix metalloproteinase-2 (MMP-2) mRNA and (E2) protein; (F1) Expression level of MMP-9 mRNA and (F2) protein in various treatment groups. ${ }^{*} P<0.05$, ${ }^{* *} P<0.01,{ }^{* *} P<0.001$, vs. control group; ${ }^{\#} P<0.05$, ${ }^{\# \#} P<0.01$, vs. ethanol group; ${ }^{\$} P<0.01,{ }^{\$} P<0.001$, vs. ethanol $+\mathrm{CCl}_{4}$ group. $\mathrm{CCl}_{4}$, ccarbon tetrachloride; WY, WY14643.

event triggering the process of liver fibrogenesis. A variety of proinflammatory and profibrogenic factors are involved in controlling the activation and proliferation of HSCs. TNF- $\alpha$, a pivotal inflammatory cytokine, exerts a profibrogenic function by inducing HSCs activation and inhibiting HSCs apoptosis [11]. We found that hepatic expression of TNF- $\alpha$ was increased in mice fed with ethanol liquid diet and intraperitoneally injected with $\mathrm{CCl}_{4}$, which was significantly reduced by WY14643 treatment. In addition, we demonstrated that hepatic expression of OPN and TGF- $\beta 1$ was up-regulated by ethanol with or without $\mathrm{CCl}_{4}$ treatment and restored by WY14643 administration. OPN is a chemoattractant molecule engaged in the hepatic inflammatory response by promoting neutrophil infiltration in the liver [12]. As a biomarker of fibrosis [13], OPN can bind to integrin on the surface of HSCs to drive the fibrogenic response by regulating collagen I deposition [14,15]. TGF- $\beta 1$ is the most critical profibrogenic factor involved in the initiation and maintenance of liver fibrogenesis $[4,16]$. It was reported that TGF- $\beta 1$ increased expression of OPN [17], which in turn up-regulated TGF- $\beta 1$ expression and activated HSCs through TGF- $\beta 1 /$ Smad pathway [18], 

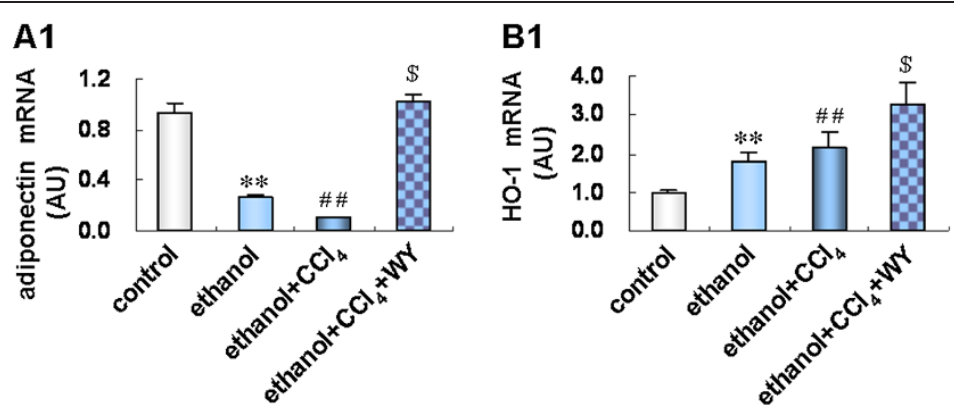

A2

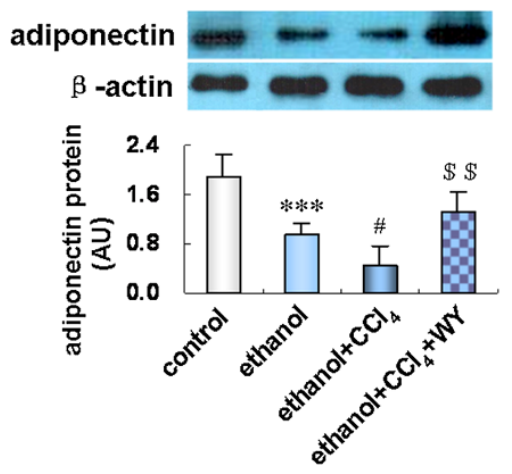

B2

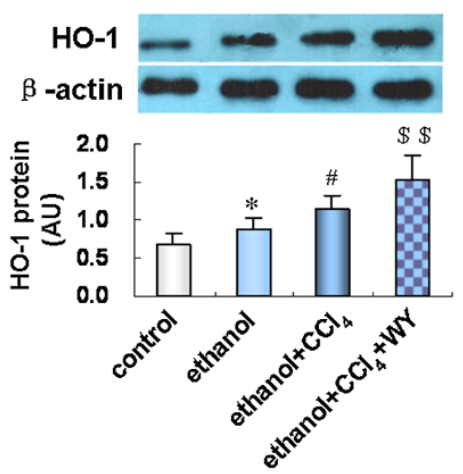

Figure 6 Effect of peroxisome proliferators activated receptor alpha (PPARa) induction on hepatic protein expression of anti-fibrotic factors. (A1) Expression level of adiponectin mRNA and (A2) protein; (B1) Expression level of heme oxygenase-1 (HO-1) mRNA and (B2) protein in various treatment groups. ${ }^{*} P<0.05$, ${ }^{* *} P<0.01$, ${ }^{* *} P<0.001$, vs. control group; ${ }^{\#} P<0.05,{ }^{\# \#} P<0.01$, vs. ethanol group; ${ }^{\$} P<0.01$, ${ }^{\$} P<0.001$, vs. ethanol $+\mathrm{CCl}_{4}$ group. $\mathrm{CCl}_{4}$, carbon tetrachloride; WY, WY14643.

forming a vicious circle promoting liver fibrogenesis. Thus, the role of PPAR $\alpha$ induction in alleviating alcoholic fibrotic hepatitis was possibly related to the down-regulation of TNF- $\alpha$, OPN and TGF- $\beta 1$, as well as the subsequent suppression of inflammatory response and fibrogenesis.

To further clarify the mechanism by which PPAR $\alpha$ alleviated ethanol mediated liver fibrosis in mice, hepatic expression of visfatin, a novel identified adipocytokine, was assessed. It was considered as a proinflammatory cytokine and could be up-regulated by TNF- $\alpha[19,20]$. In the livers of ethanol plus $\mathrm{CCl}_{4}$ treated mice, visfatin expression was markedly up-regulated, accompanied with increased hepatic expression of PI3K, MMP-2 and MMP-9. In accord with our results, one study reported that visfatin induced MMP-2 and MMP-9 production in endothelial cells, which was mediated by the PI3K signaling pathway [21]. MMP-2, secreted by activated HSCs, is considered a profibrotic mediator exerting proliferation and migration of HSCs [22,23], and can be up-regulated by TGF- $\beta$ and/or ROS stimulation [24,25]. Meanwhile, MMP-9 can stimulate HSCs activation and up-regulate TGF- $\beta 1$ expression $[26,27]$, which in turn induces MMP-9 expression through PI3K/Akt/nuclear factor-kappa B signaling pathway [28]. We demonstrated that PPAR $\alpha$ agonist significantly repressed hepatic expression of visfatin, and consequently reduced PI3K, MMP-2 and MMP-9 expression, thus suppressing the progression of ethanol mediated liver fibrosis.

We considered whether protective cytokines mediated the effect of PPAR $\alpha$ in alleviating ethanol induced liver injury. Indeed, we found that reduced hepatic expression of adiponectin in alcoholic liver fibrosis mice was restored by WY14643 treatment. Adiponectin exerts its anti-inflammatory property through suppressing TNF- $\alpha$ production and secretion [29], and alleviates hepatic fibrosis by maintaining quiescence of HSCs and inducting apoptosis of activated HSCs [30-32]. Adiponectin induces expression of several other protective mediators, and an IL-10/HO-1 pathway is involved in the antiinflammatory effects of adiponectin [33]. IL-10 inhibits intrahepatic fibrogenesis by suppressing production of collagen I [34,35], down-regulating expression of profibrogenic factors TGF- $\beta 1$, MMP-9 and TNF- $\alpha$ [36-38], and promoting apoptosis of activated HSCs [39]. In addition, IL-10 up-regulates HO-1 expression through the p38 mitogen-activated protein kinase pathway [40,41]. HO-1 acts as anti-oxidant and anti-fibrogenic protein in the liver. It was reported that induction of HO-1 suppressed oxidative stress and HSCs activation, thus inhibiting liver fibrogenesis in nutritional fibrotic steatohepatitis in mice [42]. In keeping with this observation, we found that IL-10 and HO-1 expression was up-regulated by WY14643, 
together with the improved liver injury induced by ethanol plus $\mathrm{CCl}_{4}$ administration. Therefore, the protective role of PPAR $\alpha$ induction against liver inflammation and fibrosis was mediated by up-regulating anti-inflammatory and anti-fibrogenic cytokines.

\section{Conclusions}

In summary, the present study demonstrated a protective role of PPAR $\alpha$ induction in experimental alcoholic liver fibrosis through down-regulating the proinflammatory and profibrogenic factors TNF- $\alpha$, OPN, TGF- $\beta 1$, visfatin, PI3K, MMP-2 and MMP-9, and up-regulating the tissue-protective cytokines adiponectin, IL-10 and HO-1. Consequently, PPAR $\alpha$ agonist administration might serve as an effective therapeutic strategy for alcoholic liver fibrosis.

\section{Materials and methods}

\section{Animals and treatments}

Eight-week-old male C57BL/6J mice were bred and housed as previously described [5]. The mice were randomly divided into 4 groups (6 mice per group): control group, mice fed with non-alcoholic control liquid diet (TROPHIC Animal Feed High-tech Co., Ltd., Nantong, China); ethanol group, mice fed with $4 \%$ ethanolcontaining Lieber-DeCarli liquid diet (TROPHIC); ethanol plus $\mathrm{CCl}_{4}$ (ethanol+ $\mathrm{CCl}_{4}$ ) group, mice fed with ethanol liquid diet, and received $5 \% \mathrm{CCl}_{4}$ (Sinopharm Chemical Reagent Co., Ltd, Shanghai, China) dissolved in olive oil (Sinopharm) intraperitoneal injection, $2 \mathrm{ml} / \mathrm{kg}$ body weight, twice a week; ethanol plus $\mathrm{CCl}_{4}$ and WY14643 (ethanol $+\mathrm{CCl}_{4}+\mathrm{WY}$ ) group, mice fed with ethanol liquid diet with WY14643 $(50 \mathrm{mg} / \mathrm{kg} / \mathrm{d}$, Cayman Chemical, Ann Arbor, MI, CA), and administrated with $5 \% \mathrm{CCl}_{4}$ intraperitoneal injection (Figure 7). The duration of the experiment was 8 weeks. The $\mathrm{CCl}_{4}$ intraperitoneal injection was administrated in the last 4 weeks, while PPAR $\alpha$ agonist WY14643 was administrated in the

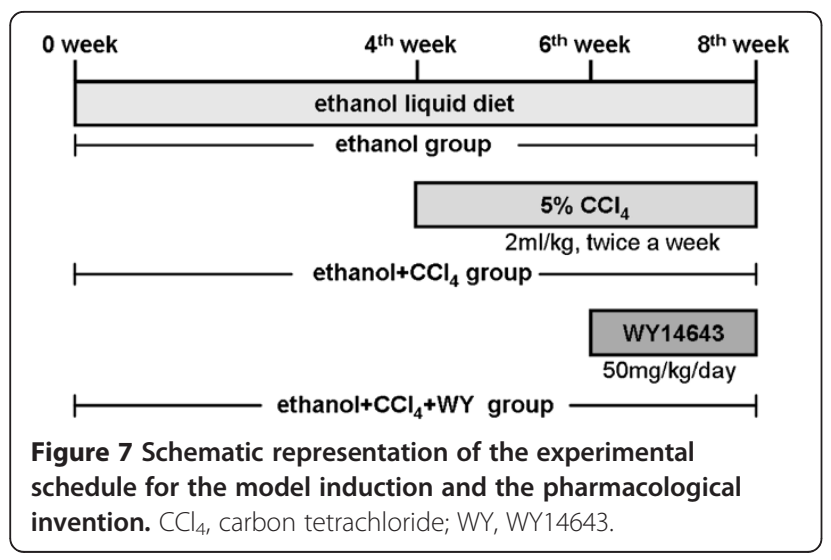

last 2 weeks. Animals were sacrificed after overnight fasting at the end of experiment. Blood samples were collected from femoral artery for biochemical analysis. Livers were weighed, and fixed in 10\% formalin for histological analysis, or snap-frozen in lipid nitrogen followed by storage at $-80^{\circ} \mathrm{C}$ in a freezer until required. All the protocols and procedures were performed following the Guidelines of the Hebei Committee for Care and Use of Laboratory Animals and were approved by the Animal Experimentation Ethics Committee of the Hebei Medical University.

\section{Biochemical analyses}

Serum ALT and AST levels were measured by the enzymatic method using an automatic biochemical analyzer (Olympus UA2700, Japan) according to the manufacturer's instructions.

Table 1 Primers used for quantitative RT-PCR analysis

\begin{tabular}{|c|c|c|}
\hline Gene & $\begin{array}{l}\text { Product } \\
\text { length }\end{array}$ & Primer sequences \\
\hline \multirow[t]{2}{*}{ PPARa } & $149 \mathrm{bp}$ & F 5'-GATGTCACACAATGCAATTCG -3' \\
\hline & & R 5'-GGTAGGCTTCGTGGATTCTCT -3' \\
\hline \multirow[t]{2}{*}{ TNF-a } & $300 \mathrm{bp}$ & F 5'-GGCAGGTCTACTTTGGAGTCATTGC-3' \\
\hline & & R 5'-ACATTCGAGGCTCCAGTGAATTCGG-3' \\
\hline \multirow[t]{2}{*}{ IL-10 } & $142 \mathrm{bp}$ & F 5'-TGCTGCCTGCTCTTACTGAC-3' \\
\hline & & R 5'-AGAAAGTCTTCACCTGGCTGA-3' \\
\hline \multirow[t]{2}{*}{ OPN } & $121 \mathrm{bp}$ & F 5'-GGTGATAGCTTGGCTTATGGAC-3' \\
\hline & & R 5'-CCTTAGACTCACCGCTCTTCAT-3' \\
\hline \multirow[t]{2}{*}{ TGF- $\beta 1$} & 272 bp & F 5'-CAACGCCATCTATGAGAAAACC-3' \\
\hline & & R 5' -ACTGCCGTACAACTCCAGTGAC-3' \\
\hline \multirow[t]{2}{*}{ visfatin } & 172 bp & F 5'- GGAAAGACCATGAGAAAGATGC-3' \\
\hline & & R 5'-CTGATGATTAGTGGTGCCTCTG-3' \\
\hline \multirow[t]{2}{*}{ PI3K } & 198 bp & F 5'- GCACGGCGATTACACTCTTAC-3' \\
\hline & & R 5'-TTGGACACTGGGTAGAGCAAC-3' \\
\hline \multirow[t]{2}{*}{ MMP-2 } & $203 \mathrm{bp}$ & F 5'- TTGTGCTGAAAGATACCCTCAA-3' \\
\hline & & R 5'-CAGGTCAGGTGTGTAACCAATG-3' \\
\hline \multirow[t]{2}{*}{ MMP-9 } & $242 \mathrm{bp}$ & F 5'-TGAATCAGCTGGCTTITGTG-3' \\
\hline & & R 5'-GTGGATAGCTCGGTGGTGTT-3' \\
\hline \multirow[t]{2}{*}{ adiponectin } & 202 bp & F 5'-CCAGTATCAGGAAAAGAATGTGG-3' \\
\hline & & R 5'-TGGTGTATGGGCTATGGGTAGT-3' \\
\hline \multirow[t]{2}{*}{ HO-1 } & $427 \mathrm{bp}$ & F 5'-AACAAGCAGAACCCAGTCTATG-3' \\
\hline & & R 5'-TGAGCAGGAAGGCGTCTTA-3' \\
\hline \multirow[t]{2}{*}{ GAPDH } & $233 \mathrm{bp}$ & F 5'-GGTGAAGGTCGGTGTGAACG-3' \\
\hline & & R 5'-CTCGCTCCTGGAAGATGGTG-3' \\
\hline
\end{tabular}

Abbreviations: PPARa, peroxisome proliferator activated receptor alpha; TNF- $a$, tumor necrosis factor-alpha; IL-10, interleukin-10; OPN, osteopontin; TGF- $\beta 1$, transforming growth factor-beta 1; PI3K, phosphatidylinositol 3-kinase; MMP-2, matrix metalloproteinase-2; MMP-9, matrix metalloproteinase-9; HO-1, heme oxygenase-1; GAPDH, glyceraldehyde-3-phosphate dehydrogenase. 


\section{Histological analysis}

Haematoxylin and eosin stained paraffin-embedded liver sections ( $5 \mu \mathrm{m}$ thick) were scored as follows: (a) degree of steatosis ( $0 \leq 10 \%, 1=10-33 \%, 2=33-66 \%$, $3 \geq 66 \%$ ); (b) degree of necroinflammation ( $0=$ none, 1 = mild, 2 = moderate, 3 = severe); (c) stage of fibrosis $(0=$ no fibrosis, $1=\mathrm{mild} /$ moderate zone 3 perisinusoidal fibrosis or portal fibrosis only, $2=$ zone 3 and portal/periportal fibrosis, $3=$ bridging fibrosis, and $4=$ cirrhosis) in accordance with a scoring system for ALD designed by Dominguez et al. [43] and the Chinese Guidelines for the diagnosis and management of alcoholic liver disease [44].

\section{Immunohistochemistry}

Immunostaining was performed in paraffin-embedded liver sections using the specific antibody and an avidinbiotin complex $(\mathrm{ABC})$ immunoperoxidase method. Briefly, after antigen repair, the primary specific antibody for $\alpha$-SMA (dilution 1: 200) (Santa Cruz Biotechnology, Santa Cruz, CA) was applied. The primary antibody was omitted and phosphate buffered saline was used as the negative control. After extensive rinsing, the biotinylated secondary antibody and ABC complex/ horseradish peroxidase were applied. Peroxidase activity was visualized by applying diaminobenzidine (Santa Cruz Biotechnology) to the sections, which were then counter-stained with hematoxylin. Quantitative analysis of $\alpha$-SMA stained liver sections (200 fold) was performed by morphometric analysis: the average area density (areas of positive cells/total areas $\times 100 \%$ ) in each section was estimated.

\section{Quantitative real-time reverse transcription polymerase chain reaction (qRT-PCR) analysis of hepatic mRNA expression}

Total RNA was isolated from liver tissues using Trizol Reagent (Tiangen Biotech, Beijing, China) according to the manufacturer's instructions. The hepatic mRNA levels of PPAR $\alpha$, TNF- $\alpha$, OPN, TGF- $\beta 1$, visfatin, PI3K, MMP-2, MMP-9, adiponectin, IL-10 and HO-1 were determined by qRT-PCR using the ABI PRISM 7500 sequence detection system (Applied Biosystems, Foster, CA) with SYBR Green Reagent (Tiangen Biotech). Expression levels of the target genes were normalized against an endogenous reference gene glyceraldehydes 3-phosphate dehydrogenase (GAPDH). The specific primer sequences were listed in Table 1. All data were obtained using Sequence Detector Software (Applied Biosystems).

\section{Western blot analysis of hepatic protein expression} Total protein was extracted and concentration was measured by the Bradford method (DC protein assay; Bio-Rad,
Hercules, CA). Equal amounts of protein (100 ìg/well) were loaded onto $12 \%$ SDS-PAGE for each sample and proteins were transferred onto equilibrated polyvinylidene difluoride membranes (Millipore Corporation, Billerica, MA) by electroblotting. The membranes were incubated with primary antibodies of PPAR $\alpha, \mathrm{OPN}, \mathrm{TGF}-\beta 1$, visfatin, PI3K, MMP-2, MMP-9, adiponectin, HO-1 and â-actin (Santa Cruz Biotechnology), respectively, overnight at $4^{\circ} \mathrm{C}$. Membranes were further incubated with secondary antibody for $1 \mathrm{~h}$ at room temperature. Proteins were detected by enhanced chemiluminescence (Santa Cruz Biotechnology). The amount of protein expression was corrected by that of â-actin in the same sample and the bands were quantified by scanning densitometry using the digital Kodak Gel Logic 200 (Carestream Molecular Imaging, Woodbridge, CT).

\section{Statistical analysis}

All data are expressed as mean \pm standard deviation (SD). Statistical analysis on the data was performed by one-way analysis of variance (ANOVA) or KruskalWallis $H$ test, with the least significant difference- $t$ (LSD- $t$ ) test or Mann-Whitney $u$ test for post-hoc comparison using SPSS 13.0 (v. 13.0; SPSS Inc., Chicago, IL), and $P$-value below 0.05 was considered significant.

\section{Abbreviations}

PPARa: Peroxisome proliferator activated receptor alpha; $\mathrm{CCl}_{4}$ : Carbon tetrachloride; HSCs: Hepatic stellate cells; MMP-2: Matrix metalloproteinase-2; MMP-9: Matrix metalloproteinase-9; ALD: Alcoholic liver disease; TNF-a: Tumor necrosis factor-alpha; TGF- 31 : Transforming growth factor-beta1; ALT: Alanine aminotransferase; AST: Aspartic transaminase; a-SMA: Alpha-smooth muscle actin; OPN: Osteopontin; PI3K: Phosphatidylinositol 3-kinase; IL-10: Interleukin-10; HO-1: Heme oxygenase-1; GAPDH: Glyceraldehyde-3-phosphate dehydrogenase.

\section{Competing interests}

The authors report no conflicts of interest. The authors alone are responsible for the content and writing of the paper.

\section{Authors' contributions}

YN designed the research; LK, WR, RW, JD, WL, SZ, YZ, WW, HD and YL performed the experiments; LK and YN analyzed data; YN, LK and JY wrote the paper. All authors read and approved the final manuscript.

\section{Acknowledgments}

This work was funded by Wang Bao-en Foundation of Hepatic Fibrosis, Chinese foundation for hepatitis prevention and control, No. 2009009.

\section{Author details}

${ }^{1}$ Department of Traditional and Western Medical Hepatology, Third Hospital of Hebei Medical University, Shijiazhuang, China. ${ }^{2}$ Institute of Digestive Disease and Department of Medicine and Therapeutics, Li Ka Shing Institute of Health Sciences, The Chinese University of Hong Kong, Shatin, Hong Kong.

Received: 30 December 2012 Accepted: 31 January 2013 Published: 6 February 2013

\section{References}

1. Cederbaum Al, LU Y, Wu D: Role of oxidative stress in alcohol-induced liver injury. Arch Toxicol 2009, 83:519-548. 
2. Lieber CS: Ethanol metabolism, cirrhosis and alcoholism. Clin Chim Acta 1997, 257:59-84.

3. Cubero FJ, Nieto N: Ethanol and arachidonic acid synergize to activate Kupffer cells and modulate the fibrogenic response via tumor necrosis factor alpha, reduced glutathione, and transforming growth factor beta-dependent mechanisms. Hepatology 2008, 48:2027-2039.

4. Cheng K, Yang N, Mahato Rl: TGF-beta1 gene silencing for treating liver fibrosis. Mol Pharm 2009, 6:772-779.

5. Kong L, Ren W, Li W, Zhao S, Mi H, Wang R, Zhang Y, Wu W, Nan Y, Yu J: Activation of peroxisome proliferator activated receptor alpha ameliorates ethanol induced hepatic steatohepatitis in mice. Lipids Health Dis 2011, 10:246.

6. Brattin WJ, Glende EA Jr, Recknage IRO: Pathological mechanisms in carbon tetracholoride hepatotoxicity. J Free Radic Biol Med 1985, 1:27-38.

7. Pan X, Hussain FN, Iqbal J, Feuerman MH, Hussain MM: Inhibiting Proteasomal Degradation of Microsomal Triglyceride Transfer Protein Prevents CCl4-induced Steatosis. J Biol Chem 2007, 282:17078-17089.

8. Ismail RS, El-Megeid AA, Abdel-Moemin AR: Carbon tetrachloride-induced liver disease in rats: the potential effect of supplement oils with vitamins E and C on the nutritional status. Ger Med Sci 2009, 7:Doc05.

9. Hall PD, Plummer JL, Ilsley AH, Cousins MJ: Hepatic fibrosis and cirrhosis after chronic administration of alcohol and "low-dose" carbon tetrachloride vapor in the rat. Hepatology 1991, 13:815-819.

10. Povero D, Busletta C, Novo E, di Bonzo LV, Cannito S, Paternostro C, Parola M: Liver fibrosis: a dynamic and potentially reversible process. Histol Histopathol 2010, 25:1075-1091

11. Tomita K, Tamiya G, Ando S, Ohsumi K, Chiyo T, Mizutani A, Kitamura N, Toda K, Kaneko T, Horie Y, Han JY, Kato S, Shimoda M, Oike Y, Tomizawa M, Makino S, Ohkura T, Saito H, Kumagai N, Nagata H, Ishii H, Hibi T: Tumour necrosis factor a signalling through activation of Kupffer cells plays an essential role in liver fibrosis of non-alcoholic steatohepatitis in mice. Gut 2006, 55:415-424.

12. Seth D, Gorrell MD, Cordoba S, McCaughan GW, Haber PS: Intrahepatic gene expression in human alcoholic hepatitis. J Hepatol 2006, 45:306-320.

13. Pritchett J, Harvey E, Athwal V, Berry A, Rowe C, Oakley F, Moles A, Mann DA, Bobola N, Sharrocks AD, Thomson BJ, Zaitoun AM, Irving WL, Guha IN, Hanley NA, Hanley KP: Osteopontin is a novel downstream target of SOX9 with diagnostic implications for progression of liver fibrosis in humans. Hepatology 2012, 56:1108-1116.

14. Tokairin T, Nishikawa Y, Watanabe H, Doi Y, Omori Y, Yoshioka T, Yamamoto Y, Yoshida M, Nishimura T, Li Q, Arai H, Ishida A, Takada G, Enomoto K: Osteopontin expression in the liver with severe perisinusoidal fibrosis: Autopsy case of Down syndrome with transient myeloproliferative disorder. Pathol Int 2008, 58:64-68.

15. Urtasun R, Lopategi A, George J, Leung TM, Lu Y, Wang X, Ge X, Fiel MI, Nieto $\mathrm{N}$ : Osteopontin, an oxidant stress sensitive cytokine, up-regulates collagen-I via integrin $\alpha(\mathrm{V}) \beta(3)$ engagement and $\mathrm{PI} 3 \mathrm{~K} / \mathrm{pAkt} / \mathrm{NFKB}$ signaling. Hepatology 2012, 55:594-608.

16. Lang Q, Liu Q, Xu N, Qian KL, Qi JH, Sun YC, Xiao L, Shi XF: The antifibrotic effects of TGF- $\beta 1$ siRNA on hepatic fibrosis in rats. Biochem Biophys Res Commun 2011, 409:448-453.

17. Ehnert S, Baur J, Schmitt A, Neumaier M, Lucke M, Dooley S, Vester H, Wildemann B, Stöckle U, Nussler AK: TGF- $\beta 1$ as possible link between loss of bone mineral density and chronic inflammation. PLoS One 2010, 5:e14073.

18. Huang L, Wei MF, Feng JX: Abnormal activation of OPN inflammation pathway in livers of children with biliary atresia and relationship to hepatic fibrosis. Eur J Pediatr Surg 2008, 18:224-229.

19. Moschen AR, Gerner R, Schroll A, Fritz T, Kaser A, Tilg H: A Key Role for Pre-B cell Colony-Enhancing Factor in Experimental Hepatitis. Hepatology 2011, 54:675-686.

20. Ognjanovic S: Genomic organization of the gene coding for human pre-B-cell colony enhancing factor and expression in human fetal membranes. J Mol Endocrinol 2001, 26:107-117.

21. Adya R, Tan BK, Punn A, Chen J, Randeva HS: Visfatin induces human endothelial VEGF and MMP-2/9 production via MAPK and PI3K/Akt signalling pathways: novel insights into visfatin-induced angiogenesis. Cardiovasc Res 2008, 78:356-365.

22. Ikeda K, Wakahara T, Wang $Y Q$, Kadoya $H$, Kawada N, Kaneda K: In vitro migratory potential of rat quiescent hepatic stellate cells and its augmentation by cell activation. Hepatology 1999, 29:1760-1767.

23. Zhou X, Hovell CJ, Pawley S, Hutchings MI, Arthur MJ, Iredale JP, Benyon RC: Expression of matrix metalloproteinase- 2 and -14 persists during early resolution of experimental liver fibrosis and might contribute to fibrolysis. Liver Int 2004, 24:492-501.

24. Galli A, Svegliati-Baroni G, Ceni E, Milani S, Ridolfi F, Salzano R, Tarocchi M, Grappone C, Pellegrini G, Benedetti A, Surrenti C, Casini A: Oxidative stress stimulates proliferation and invasiveness of hepatic stellate cells via a MMP2-mediated mechanism. Hepatology 2005, 41:1074-1084.

25. Parola M, Robino G: Oxidative stress-related molecules and liver fibrosis. J Hepatol 2001, 35:297-306.

26. Han YP, Yan C, Zhou L, Qin L, Tsukamoto H: A Matrix Metalloproteinase-9 Activation Cascade by Hepatic Stellate Cells in Trans-differentiation in the Three-dimensional Extracellular Matrix. J Biol Chem 2007, 282:12928-12939.

27. Perng DW, Chang KT, Su KC, Wu YC, Chen CS, Hsu WH, Tsai CM, Lee YC: Matrix metalloprotease- 9 induces transforming growth factor- $\beta(1)$ production in airway epithelium via activation of epidermal growth factor receptors. Life Sci 2011, 89:204-212.

28. Zhu X, Wang L, Zhang B, Li J, Dou X, Zhao RC: TGF-beta1-induced PI3K Akt/NF-kappaB/MMP9 signalling pathway is activated in Philadelphia chromosome-positive chronic myeloid leukaemia hemangioblasts. J Biochem 2011, 149:405-414.

29. Thakur V, Pritchard MT, McMullen MR, Nagy LE: Adiponectin normalizes LPS-stimulated TNF-alpha production by rat Kupffer cells after chronic ethanol feeding. Am J Physiol 2006, 290:G998-1007.

30. Tomita K, Oike Y, Teratani T, Taguchi T, Noguchi M, Suzuki T, Mizutani A, Yokoyama H, Irie R, Sumimoto H, Takayanagi A, Miyashita K, Akao M, Tabata M, Tamiya G, Ohkura T, Hibi T: Hepatic adipoR2 signaling plays a protective role against progression of nonalcoholic steatohepatitis in mice. Hepatology 2008, 48:458-473.

31. Ding X, Saxena NK, Lin S, XU A, Srinivasan S, Anania FA: The roles of leptin and adiponectin: a novel paradigm in adipocytokine regulation of liver fibrosis and stellate cell biology. Am J Pathol 2005, 166:1655-1669.

32. Wu CW, Chu ES, Lam CN, Cheng AS, Lee CW, Wong WW, Sung JJ, Yu J: PPARgamma is essential for protection against nonalcoholic steatohepatitis. Gene Ther 2010, 17:790-798.

33. Mandal P, Pritchard MT, Nagy LE: Anti-inflammatory pathways and alcoholic liver disease: role of an adiponectin/interleukin-10/heme oxygenase-1 pathway. World J Gastroenterol 2010, 16:1330-1336.

34. Zheng WD, Zhang $\sqcup$, Shi MN, Chen ZX, Chen YX, Huang YH, Wang XZ: Expression of matrix metalloproteinase- 2 and tissue inhibitor of metalloproteinase- 1 in hepatic stellate cells during rat hepatic fibrosis and its intervention by IL-10. World J Gastroenterol 2005, 11:1753-1758.

35. Zhang $L J$, Chen $Y X$, Chen ZX, Huang YH, Yu JP, Wang XZ: Effect of interleukin-10 and platelet-derived growth factor on expressions of matrix metalloproteinases- 2 and tissue inhibitor of metalloproteinases- 1 in rat fibrotic liver and cultured hepatic stellate cells. World J Gastroenterol 2004, 10:2574-2579.

36. Zhang LJ, Zheng WD, Chen YX, Huang YH, Chen ZX, Zhang SJ, Shi MN, Wang XZ: Antifibrotic effects of interleukin-10 on experimental hepatic fibrosis. Hepatogastroenterology 2007, 54:2092-2098.

37. Zhang LJ, Yu JP, Li D, Huang YH, Chen ZX, Wang XZ: Effects of cytokines on carbon tetrachloride-induced hepatic fibrogenesis in rats. World J Gastroenterol 2004, 10:77-81.

38. Kovalovich K, DeAngelis RA, Li W, Furth EE, Ciliberto G, Taub R: Increased toxin-induced liver injury and fibrosis in interleukin-6-deficient mice. Hepatology 2000, 31:149-159.

39. Wang XZ, Zhang SJ, Chen YX, Chen ZX, Huang YH, Zhang L: Effects of platelet-derived growth factor and interleukin-10 on Fas/Fas-ligand and $\mathrm{Bcl}-2 / \mathrm{Bax}$ mRNA expression in rat hepatic stellate cells in vitro. World J Gastroenterol 2004, 10:2706-2710.

40. Gómez-Hurtado I, Zapater P, Bellot P, Pascual S, Pérez-Mateo M, Such J, Francés R: Interleukin-10-Mediated Heme Oxygenase 1-Induced Underlying Mechanism in Inflammatory Down-Regulation by Norfloxacin in Cirrhosis. Hepatology 2011, 53:935-944.

41. Drechsler Y, Dolganiuc A, Norkina O, Romics L, Li W, Kodys K, Bach FH, Mandrekar P, Szabo G: Heme oxygenase-1 mediates the anti-inflammatory effects of acute alcohol on IL-10 induction involving p38 MAPK activation in monocytes. J Immunol 2006, 177:2592-2600.

42. Wang RQ, Nan YM, Wu WJ, Kong LB, Han F, Zhao SX, Kong L, Yu J: Induction of heme oxygenase-1 protects against nutritional fibrosing steatohepatitis in mice. Lipids Health Dis 2011, 10:31.

43. Dominguez M, Rincón D, Abraldes JG, Miquel R, Colmenero J, Bellot $P$, García-Pagán JC, Fernández R, Moreno M, Bañares R, Arroyo V, Caballería J, 
Ginès $P$, Bataller R: A new scoring system for prognostic stratification of patients with alcoholic hepatitis. Am J Gastroenterol 2008, 103:2747-2756

44. The Chinese National Workshop on Fatty Liver and Alcoholic Liver Disease for the Chinese Liver Disease Association: Guideline for management of alcoholic liver disease: a update and revised edition. Zhonghua Ganzangbing Zazhi 2010, 18:167-170.

doi:10.1186/1476-511X-12-11

Cite this article as: Nan et al: Activation of peroxisome proliferator activated receptor alpha ameliorates ethanol mediated liver fibrosis in mice. Lipids in Health and Disease 2013 12:11.

\section{Submit your next manuscript to BioMed Central and take full advantage of:}

- Convenient online submission

- Thorough peer review

- No space constraints or color figure charges

- Immediate publication on acceptance

- Inclusion in PubMed, CAS, Scopus and Google Scholar

- Research which is freely available for redistribution 